\title{
Genome-wide prediction and prioritization of human aging genes by data fusion: a machine learning approach
}

\author{
Masoud Arabfard ${ }^{1,2}$, Mina Ohadi $^{3^{*}}$, Vahid Rezaei Tabar ${ }^{4}$, Ahmad Delbari $^{3}$ and Kaveh Kavousi ${ }^{2^{*}}$ (D)
}

\begin{abstract}
Background: Machine learning can effectively nominate novel genes for various research purposes in the laboratory. On a genome-wide scale, we implemented multiple databases and algorithms to predict and prioritize the human aging genes (PPHAGE).

Results: We fused data from 11 databases, and used Naïve Bayes classifier and positive unlabeled learning (PUL) methods, NB, Spy, and Rocchio-SVM, to rank human genes in respect with their implication in aging. The PUL methods enabled us to identify a list of negative (non-aging) genes to use alongside the seed (known age-related) genes in the ranking process. Comparison of the PUL algorithms revealed that none of the methods for identifying a negative sample were advantageous over other methods, and their simultaneous use in a form of fusion was critical for obtaining optimal results (PPHAGE is publicly available at https://cbb.ut.ac.ir/pphage).

Conclusion: We predict and prioritize over 3,000 candidate age-related genes in human, based on significant ranking scores. The identified candidate genes are associated with pathways, ontologies, and diseases that are linked to aging, such as cancer and diabetes. Our data offer a platform for future experimental research on the genetic and biological aspects of aging. Additionally, we demonstrate that fusion of PUL methods and data sources can be successfully used for aging and disease candidate gene prioritization.
\end{abstract}

Keywords: Genome-wide, Prioritization, Human aging genes, Positive unlabeled learning, Machine learning

\section{Background}

Prior understanding of the genetic basis of a disease is a crucial step for the better diagnosis and treatment of the disease [1]. Machine learning methods help specialists and biologists the use of functional or inherent properties of genes in the selection of candidate genes [2]. Perhaps the question that is posed to researchers is why all research is aimed at identifying pathogenic rather than non-pathogenic genes. The answer may lie in the fact that genes introduced as non-pathogens may be documented as disease genes later on.

\footnotetext{
*Correspondence: mi.ohadi@uswr.ac.ir; ohadi.mina@yahoo.com; kkavousi@ut.ac.ir

${ }^{3}$ Iranian Research Center on Aging, University of Social Welfare and Rehabilitation Sciences, Tehran, Iran

${ }^{2}$ Laboratory of Complex Biological Systems and Bioinformatics (CBB), Department of Bioinformatics, Institute of Biochemistry and Biophysics (IBB), University of Tehran, Tehran, Iran

Full list of author information is available at the end of the article
}

Biologists apply computation, mathematics methods, and algorithms to develop machine learning methods of identifying novel candidate disease genes [3]. Based on the principle of "guilt by association", similar or identical diseases share genes that are very similar in function or intrinsic properties, or have direct physical proteinprotein interactions [4]. Most methods of predicting candidate genes employ various biological data, such as protein sequence, functional annotation, gene expression, protein-protein interaction networks, regulatory data and even orthogonal and conservation data, to identify similarities with respect to the principle of association based on similarity [5]. These methods are categorized as unsupervised, supervised, and semisupervised [6]. Unsupervised methods cluster the genes based on their proximity and similarity to the known disease genes, and rank them by various methods. Supervised methods create a boundary between disease genes and non-disease genes, and utilize this boundary 
Table 1 Datasets used to evaluate reliable negative sample extraction algorithms

\begin{tabular}{lll}
\hline Number of instances & Number of attributes & Data set names \\
\hline 756 & 754 & Parkinson's Disease Classification Data Set [19] \\
345 & 7 & Liver Disorders Data Set [20] \\
1024 & 10 & Cloud Data Set [21] \\
351 & 34 & lonosphere Data Set [22] \\
19,020 & 11 & MAGIC Gamma Telescope Data Set [23] \\
961 & 6 & Mammographic Mass Data Set [24] \\
569 & 32 & Breast Cancer Wisconsin (Diagnostic) Data Set [25] \\
208 & 60 & Connectionist Bench (Sonar, Mines vs. Rocks) Data Set [26]
\end{tabular}

to select candidate genes. Several studies have been performed to address different aspects of the methodology and have expanded the use of various methods and tools $[3,7-12]$.

The tools that are available for candidate gene prioritization can be classified with respect to efficiency, computational algorithms, data sources, and availability [13-15]. Available prioritization tools can be categorized into specific and general tools [16]. Specific tools are used to prioritize candidate genes associated with a specific disease. In these methods, information related to a specific tissue involved in the disease or other information related to the disease is employed. General tools can be applied for most diseases, and various data sources are often used in these tools. Gene prioritization tools can be divided into two types of single-species and multi-species. Single-species tools are only usable for a specific species, such as human or mouse. Multi-species tools have the ability to prioritize candidate genes in several different species. For example, the ENDEAVOR

Table 2 Performance evaluation of the reliable negative sample extraction algorithms

\begin{tabular}{|c|c|c|c|c|c|c|}
\hline Data set & Algorithm & FPR\% & FNR\% & Precision \% & Recall \% & F_measure $\%$ \\
\hline \multirow[t]{3}{*}{ Parkinson's Disease } & NB & 37.25 & 4.57 & 95.43 & 89.78 & 92.52 \\
\hline & SPY & 8.70 & 16.11 & 97.42 & 83.89 & 90.15 \\
\hline & Roc-SVM & 6.52 & 15.00 & 98.08 & 85.00 & 91.07 \\
\hline \multirow[t]{3}{*}{ Liver Disorders } & NB & 17.65 & 5.71 & 73.33 & 94.29 & 82.50 \\
\hline & SPY & 36.14 & 0 & 40.00 & 100 & 57.14 \\
\hline & Roc-SVM & 31.33 & 5.00 & 42.22 & 95.00 & 58.46 \\
\hline \multirow[t]{3}{*}{ Cloud } & NB & 18.88 & 7.93 & 84.83 & 92.07 & 88.30 \\
\hline & SPY & 9.52 & 14.92 & 92.77 & 85.08 & 88.76 \\
\hline & Roc-SVM & 6.32 & 16.51 & 96.72 & 83.49 & 89.62 \\
\hline \multirow[t]{3}{*}{ Ionosphere } & NB & 47.62 & 8.33 & 88.51 & 91.67 & 90.06 \\
\hline & SPY & 26.32 & 6.98 & 94.12 & 93.02 & 93.57 \\
\hline & Roc-SVM & 33.33 & 8.89 & 94.25 & 91.11 & 92.66 \\
\hline \multirow[t]{3}{*}{ MAGIC Gamma Telescope } & NB & 10.49 & 44.44 & 68.18 & 55.56 & 61.22 \\
\hline & SPY & 17.88 & 36.22 & 53.88 & 63.78 & 58.42 \\
\hline & Roc-SVM & 6.68 & 47.18 & 77.65 & 52.82 & 62.87 \\
\hline \multirow[t]{3}{*}{ Mammographic Mass } & NB & 7.25 & 33.72 & 85.07 & 66.28 & 74.51 \\
\hline & SPY & 11.96 & 10.00 & 62.07 & 90.00 & 73.47 \\
\hline & Roc-SVM & 1.95 & 28.57 & 94.34 & 71.43 & 81.30 \\
\hline \multirow[t]{3}{*}{ Breast Cancer Wisconsin } & NB & 13.85 & 12.26 & 91.18 & 87.74 & 89.42 \\
\hline & SPY & 9.09 & 10.48 & 94.00 & 89.52 & 91.71 \\
\hline & Roc-SVM & 22.50 & 22.14 & 91.89 & 77.86 & 84.30 \\
\hline \multirow[t]{3}{*}{ Connectionist Bench (Sonar, Mines vs. Rocks) } & NB & 13.85 & 12.26 & 91.18 & 87.74 & 89.42 \\
\hline & SPY & 16.67 & 7.69 & 80.00 & 92.31 & 85.71 \\
\hline & Roc-SVM & 22.50 & 22.14 & 91.89 & 77.86 & 84.30 \\
\hline
\end{tabular}


Table 3 Model performance evaluation by Naïve Bayes on the aging data

\begin{tabular}{llllll}
\hline & Precision \% & Recall \% & $\mathrm{F}$ measure \% & Accuracy \% & AUC \% \\
\hline Train & 80.78 & 76.95 & 78.81 & 78.52 & 83.81 \\
Test & 87.09 & 81.82 & 84.37 & 84.13 & 88.99 \\
\hline
\end{tabular}

software can prioritize the candidate genes in six different species [17]. With respect to computational algorithms, candidate prioritization tools are primarily divided into two groups of complex network-based methods and similarity-based methods [5]. The inevitable completeness and existence of errors in biological data sources necessitate fusion of multiple data sources [18]. Most gene targeting methods, therefore, use multiple data sources to improve performance.

The purpose of this study was to design a machine to identify and prioritize novel candidate aging genes in human. We examined the existing methods of identifying human non-aging (negative) genes in the machine learning techniques, and then made a binary classifier for predicting novel candidate genes, based on the positively and negatively learned genes. Gene ranking was based on the principle of the similarity among positive genes through "guilt by association". Thus, across the unlabeled genes, genes that were less similar in respect with the known genes were employed as negative sample.

\section{Results}

The three positive unlabeled learning (PUL) algorithms, Naïve Bayes (NB), Spy, and Rocchio-SVM, were used to evaluate the underlying data, and to compare them to the eight datasets introduced with respect to performance. All samples of a class with a higher frequency were unlabeled. We applied the algorithm to predict the labels. These methods utilize a two-step strategy and are intended to extract a reliable negative sample from the main data (Table 1).

We also randomly selected $70 \%$ of the positive samples as the training set, and the remainder as the test set. To determine the classifier, positive and negative samples were equally selected to ensure that the classifier did not have any bias at the training step. Therefore, we compared the three algorithms with eight data sources extracted from the UCI database (Additional file 1).

Comparison of the parameters of the three algorithms for all data sets revealed similar results in F measure. For example, in data set 1 , the precision of the Roc-SVM method, (approximately 2-3\%,) was better than those of the other two methods. However, the recall of the NB method (approximately 4-6\%,) was better than those of the other two methods, and Roc-SVM method had a lower false positive rate than that of the other two methods (Table 2). In addition, comparison between the parameters of the three algorithms for data set 2, revealed that the precision of the NB method was better than that of the other two methods, the recall SPY method was $5 \%$ better than that of the other two methods, and the NB method had a lower false positive rate than that of the other two methods. Therefore, none of the methods had an absolute superiority. Since the results were very similar, the output of the three methods was combined.

The three PUL algorithms were applied to extract reliable negative samples and to compare them with respect to performance. In this algorithm, only 303 positive samples were given as input, which enabled extraction of reliable negative samples from the remaining data. Subsequently, from the positive and negative data, a new

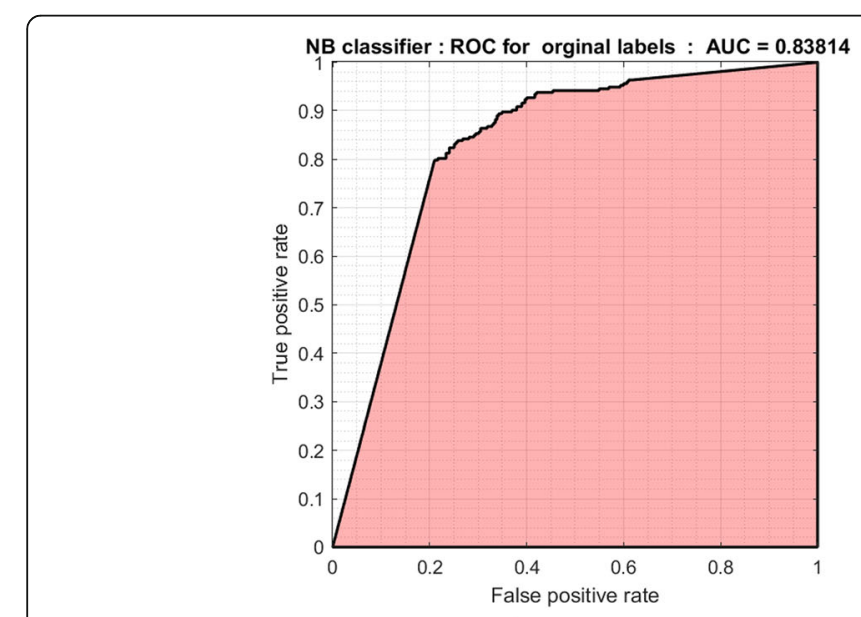

a)Training

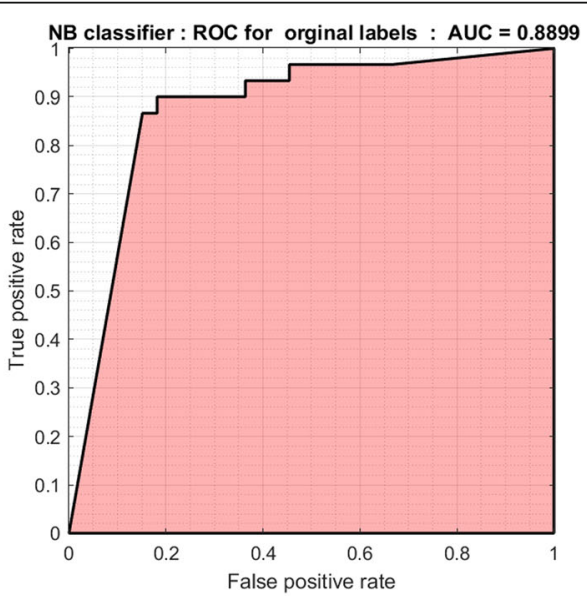

b)Test

Fig. 1 ROC curves. ROC was performed to evaluate the performance of the Naïve Bayes model at the training and test steps, which resulted in similar values for both curves 
Table 4 Performance evaluation comparison by multiple binary classifier in the aging data

\begin{tabular}{lllllll}
\hline & $\begin{array}{l}\text { TP rate } \\
\%\end{array}$ & $\begin{array}{l}\text { FP } \\
\text { rate\% }\end{array}$ & $\begin{array}{l}\text { Precision } \\
\%\end{array}$ & $\begin{array}{l}\text { Recall } \\
\%\end{array}$ & $\begin{array}{l}\text { F measure } \\
\%\end{array}$ & $\begin{array}{l}\text { AUC } \\
\%\end{array}$ \\
\hline SVM & 80 & 21.1 & 82 & 80 & 79.6 & 79.5 \\
libD3C & 85.1 & 15.3 & 85.3 & 85.1 & 85 & 91.9 \\
NB & 81.1 & 19.7 & 82.4 & 81.1 & 80.9 & 86 \\
\hline
\end{tabular}

classifier was trained to identify novel candidate genes to be utilized for prioritization and ranking. A total of 328 negative genes were extracted from each positive and negative gene, with a threshold of 11 replicates per negative gene (Additional file 2), and the Naïve Bayes binary classifiers were trained in a 10-fold cross-validation (Table 3). Additional file 2 contains results for all thresholds. The ROC chart for training and test data is shown in Fig. 1.

We trained multiple binary classifiers using all features in the positive genes and reliable negative data to compare the NB classifier to other classifiers. We investigated the performance of binary SVM [27], NB, and libD3C [28] classifiers in the dataset with 10-Fold cross validation, using Weka [29]. All classifiers had similar performance in the main data set (Table 4).

A major challenge in classification is to reduce the dimensionality of the feature space. Some methods, such as PCA, are linear combinations of the original features. In this research, we investigated the PCA method in the final model, which eliminated some of the original input features and retained a minimum subset of features that yielded the best classification performance. In addition, the feature selection technique was used to select the best subset of features that were satisfying to the model in respect with the subset of the main features. A fixed number of top ranked features were selected to design a classifier. A suitable technique for feature selection is minimal-redundancy-maximal-relevance (mRMR) [30]. We also used mRMR for feature selection in the main data, and then compared multiple binary classifiers in the positive and reliable negative genes. We investigated the top 500 ranked features that were extracted from the mRMR tool to compare the classifiers. All of the selected classifiers yielded acceptable results (Table 5).

Table 5 Performance evaluation comparison by multiple binary classifier in the aging data after feature selection

\begin{tabular}{lllllll}
\hline & $\begin{array}{l}\text { TP rate } \\
\%\end{array}$ & $\begin{array}{l}\text { FP } \\
\text { rate\% }\end{array}$ & $\begin{array}{l}\text { Precision } \\
\%\end{array}$ & $\begin{array}{l}\text { Recall } \\
\%\end{array}$ & $\begin{array}{l}\text { F measure } \\
\%\end{array}$ & $\begin{array}{l}\text { AUC } \\
\%\end{array}$ \\
\hline SVM & 83.5 & 17.1 & 84.2 & 83.5 & 83.4 & 83.2 \\
libD3C & 84.6 & 15.7 & 84.8 & 84.6 & 84.6 & 92.3 \\
NB & 81.9 & 18.5 & 82.1 & 81.9 & 81.9 & 86.8 \\
\hline
\end{tabular}

Table 6 Number of detected seed genes in comparison to the output of tools

\begin{tabular}{lllll}
\hline Tools & Rank & Fold1 & Fold2 & Fold3 \\
\hline Endeavour & $<10$ & 1 & 0 & 1 \\
& $<50$ & 2 & 0 & 2 \\
& $<100$ & 4 & 1 & 2 \\
& $<500$ & 11 & 12 & 17 \\
& $<1000$ & 24 & 25 & 25 \\
ToppGene & $<10$ & 2 & 0 & 1 \\
& $<50$ & 11 & 0 & 2 \\
& $<100$ & 16 & 1 & 2 \\
PPHAGE & $<500$ & 44 & 12 & 17 \\
& $<1000$ & 62 & 25 & 25 \\
& $<10$ & 2 & 2 & 0 \\
& $<50$ & 7 & 4 & 5 \\
& $<100$ & 12 & 12 & 9 \\
& $<500$ & 50 & 35 & 38 \\
& $<1000$ & 66 & 61 & 67 \\
\hline
\end{tabular}

Model accuracy assurance is very difficult when the model applied to a separate test suite includes positive and unlabeled samples. This challenge is critical in instances which lack negative sample. Thus, we compared the evaluation metric with the data. We generated data for all 10 models in the training section to predict the residual genes, and extracted the genes that were identified by the 10 models as positive genes, yielding a total of 3531 final candidate genes.

To compare the output of the method with the known tools for prioritizing the genes, the output of the model was compared with two softwares, Endeavor [17] and ToppGene [31], in the seed genes.

(the list of seed genes in the form of K-Fold with $\mathrm{K}=3$ was utilized for the mentioned tools). Two metrics for comparing the tools with the proposed model were considered. The first metric calculated the average ranking for the seed genes, and the second metric determined the number of seed genes on the lists as 10, 50, 100, 500, and 1000 .

A tool that had more seed genes at the top of the list and a lower average rating compared with the remaining tools, received a higher ranking. Table 6 shows the output of the tools and the PPHAGE method for determining the number of test genes on the known lists. Table 7

Table 7 Average rank of the seed genes in comparison to the output of tools

\begin{tabular}{llll}
\hline & Fold1 & Fold2 & Fold3 \\
\hline Endeavour & 1851 & 1918 & 1877 \\
ToppGene & 926 & 849 & 1024 \\
PPHAGE & 833 & 919 & 930 \\
\hline
\end{tabular}


Table 8 The top 25 human candidate aging genes

\begin{tabular}{|c|c|c|c|c|}
\hline Rank & Gene symbol & Relevance & Reference & Database reference \\
\hline 1 & NAPIL4 & Nucleosome Assembly & {$[32,33]$} & \\
\hline 2 & $\begin{array}{l}\text { CCNI } \\
\text { (CYC1) }\end{array}$ & Parkinson Disease & [34] & BEFREE \\
\hline 3 & RPL3 & Ribosomal Protein & [35] & \\
\hline 4 & FZD5 & Alzheimer's Disease & {$[36]$} & BEFREE \\
\hline 5 & BRD2 & $\begin{array}{l}\text { Diabetes Mellitus, Non-Insulin-Dependent } \\
\text { Osteoporosis, Postmenopausal } \\
\text { Colorectal Cancer }\end{array}$ & {$[37-40]$} & BEFREE \\
\hline 6 & ATP8A2 & ATPase Phospholipid Transporting & [41] & \\
\hline 7 & SRSF11 & Serine And Arginine Rich Splicing Factor & [42] & \\
\hline 8 & $B B \mid P 1$ & & & \\
\hline 9 & 1410 & $\begin{array}{l}\text { Cardiovascular Diseases } \\
\text { Diabetes Mellitus, Non-Insulin-Dependent } \\
\text { Colorectal Cancer } \\
\text { Atherosclerosis } \\
\text { Parkinson Disease } \\
\text { Alzheimer's Disease } \\
\text { Arthritis } \\
\text { Heart failure }\end{array}$ & $\begin{array}{l}{[43,44]} \\
{[45-47]} \\
{[48,49]} \\
{[50,51]} \\
{[52-54]} \\
{[55-57]} \\
{[58-60]} \\
{[61-63]}\end{array}$ & $\begin{array}{l}\text { CTD_human } \\
\text { RGD } \\
\text { LHGDN } \\
\text { BEFREE } \\
\text { HPO }\end{array}$ \\
\hline 10 & FYCO1 & $\begin{array}{l}\text { Cataract, autosomal recessive congenital } 2 \\
\text { Cataract }\end{array}$ & {$[64,65]$} & $\begin{array}{l}\text { UNIPROT } \\
\text { GENOMICS_ENGLAND } \\
\text { HPO } \\
\text { CTD_human }\end{array}$ \\
\hline 11 & PSMB2 & & & \\
\hline 12 & NSF & Parkinson Disease & {$[66-70]$} & $\begin{array}{l}\text { GWASDB } \\
\text { GWASCAT } \\
\text { BEFREE }\end{array}$ \\
\hline 13 & OAZ1 & & & \\
\hline 14 & ZFP36L1 & & & \\
\hline 15 & PCLO & Diabetes Mellitus, Non-Insulin-Dependent & [71] & BEFREE \\
\hline 16 & GAB2 & $\begin{array}{l}\text { Alzheimer's Disease } \\
\text { Colorectal Cancer } \\
\text { Osteopetrosis }\end{array}$ & $\begin{array}{l}{[72-75]} \\
{[76,77]} \\
{[78]}\end{array}$ & $\begin{array}{l}\text { BEFREE } \\
\text { GWASDB } \\
\text { GWASCAT }\end{array}$ \\
\hline 17 & QKI & $\begin{array}{l}\text { Coronary heart disease } \\
\text { Colorectal Cancer }\end{array}$ & [79] & $\begin{array}{l}\text { BEFREE } \\
\text { UNIPROT }\end{array}$ \\
\hline 18 & ZNF638 & & & \\
\hline 19 & RGS3 & & & \\
\hline 20 & XPO6 & & & \\
\hline 21 & ATP8B1 & Colorectal Cancer & {$[80]$} & BEFREE \\
\hline 22 & ITM2C & & & \\
\hline 23 & RBFOX1 & $\begin{array}{l}\text { Heart failure } \\
\text { Colorectal Cancer }\end{array}$ & $\begin{array}{l}{[81]} \\
{[82]}\end{array}$ & BEFREE \\
\hline 24 & DLC1 & $\begin{array}{l}\text { Colorectal Cancer } \\
\text { Hereditary Diffuse Gastric Cancer } \\
\text { Coronary heart disease } \\
\text { Increased gastric cancer }\end{array}$ & $\begin{array}{l}{[83]} \\
{[84]} \\
{[85]}\end{array}$ & $\begin{array}{l}\text { BEFREE } \\
\text { CTD_human } \\
\text { HPO }\end{array}$ \\
\hline 25 & MVK & $\begin{array}{l}\text { Arthritis } \\
\text { Cataract }\end{array}$ & & $\begin{array}{l}\mathrm{HPO} \\
\mathrm{HPO}\end{array}$ \\
\hline
\end{tabular}

shows the output of tools and the PPHAGE method for the average rank score on different lists.

The top 25 genes that received the highest weight among all candidate aging genes (Table 8), were validated in a number of instances, based on experimental evidence, age-related diseases, and genome-wide association studies (GWAS). A list of all candidate positive aging genes is provided in Additional file 3.

\section{Discussion}

On a genome-wide scale, we used three PUL methods to create a method for the isolation of human aging genes from other genes. The combined use of several methods as a fusion of their output was advantageous over using one single method.

Following are examples of the identified genes and experimental or GWAS link between these genes and 
Table 9 Indicative diseases associated with the candidate aging genes

\begin{tabular}{llllll}
\hline Index & Name & P-value & $\begin{array}{l}\text { Adjusted } \\
p \text {-value }\end{array}$ & Z-score & Combined score \\
\hline 1 & & & 0.000001256 & -1.94 & 35.07 \\
2 & Colorectal cancer & $1.43 \mathrm{e}-08$ & 0.00002953 & -1.64 & 23.32 \\
3 & Leukemia & $6.71 \mathrm{e}-07$ & 0.0002357 & -1.45 & 16.76 \\
4 & 0.000009246 & 0.0002986 & -0.92 & 9.85 \\
5 & Breast_cancer & 0.00002362 & 0.0002986 & -0.9 & 9.68 \\
6 & Diabetes & 0.00002185 & 0.0002986 & -0.59 & 6.23 \\
\hline
\end{tabular}

aging. On the list of the 25 top genes, NAP1L4 encodes a member of the nucleosome assembly protein (NAP) family, which interacts with both core and linker histones, and shuttles between the cytoplasm and nucleus, suggesting a role as histone chaperone. Histone protein levels decline during aging, and dramatically affect chromatin structure. Remarkably, the lifespan can be extended by manipulations that reverse the age-dependent changes to chromatin structure, indicating the pivotal role of chromatin structure in aging [32]. In another example, gene expression of NAP1L4 increases with age in the skin tissue [33]. Findings of GWAS link a number of the identified genes to age-related disorders, such as $G A B 2$ and late onset Alzheimer's disease [86], and $Q K I$ and coronary heart disease/myocardial infarction [79]. Interestingly, GWAS reports also link QKI to successful aging [87].

RPL3 encodes a ribosomal protein that is a component of the $60 \mathrm{~S}$ subunit. The encoded protein belongs to the L3P family of ribosomal proteins, and is increased in gene expression during aging of skeletal muscle [88]. In another example, FZD5 is involved in prostate cancer, which is the most common malignancy in older men. ATP8A2 is another gene subject to deterioration and loss of function over time. RYR2 (Additional file 3) encodes a ryanodine receptor found in cardiac muscle sarcoplasmic reticulum. Mutations in this gene are associated with stress-induced polymorphic ventricular tachycardia and arrhythmogenic right ventricular dysplasia and methylation analysis of CpG sites in DNA from blood cells showed a positive correlation between $R Y R 2$ and age [89]. In additional examples, differential expression with age was identified in BCAS3, TUFM and DST in the skin [33]. Gene expression revealed a significant increase in the expression of hippocampal TLR3 from elderly (aged 69-99 years old) compared to cells from younger individuals (aged 20-52 years old) [90]. Similarly, differential expression with age was identified in RORA in the adipose tissue [33].

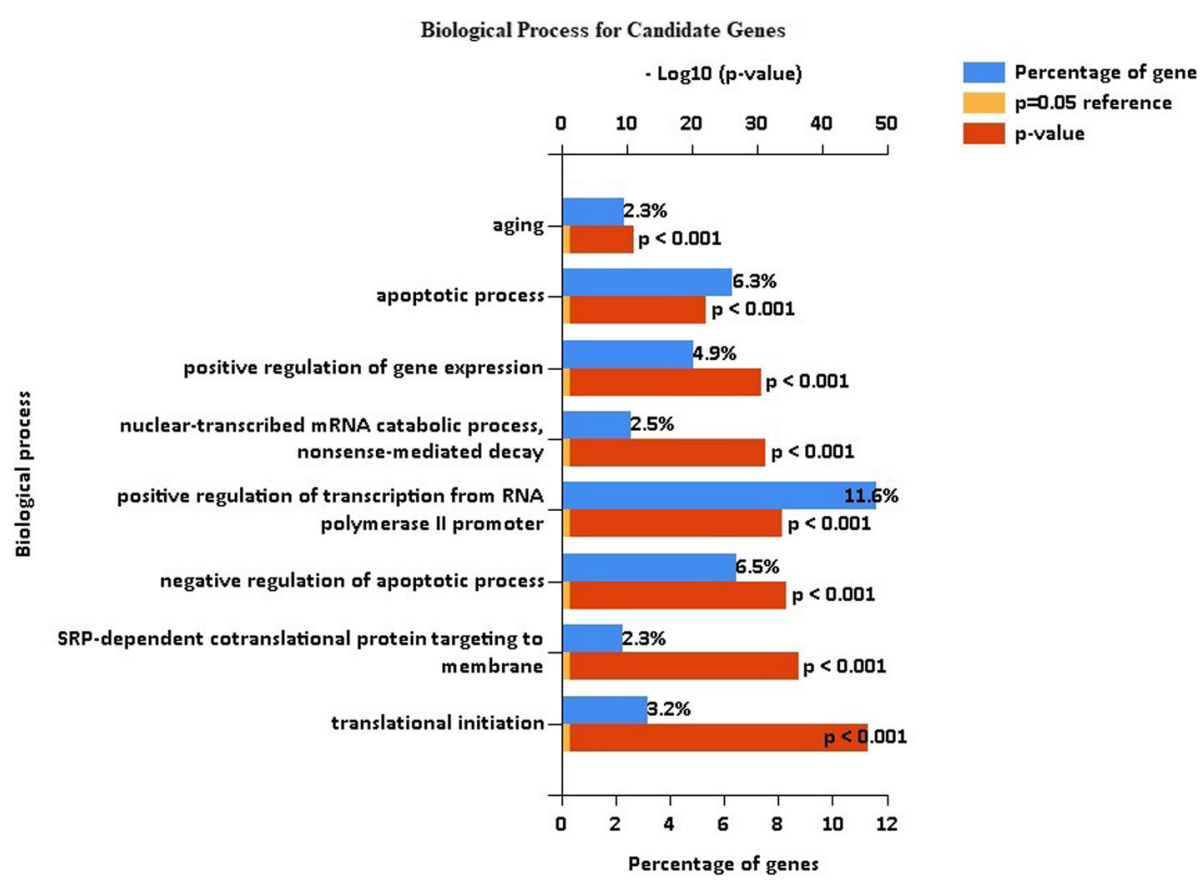

Fig. 2 Significant biological processes associated with the candidate aging genes 
Table 10 Indicative biological pathways associated with the candidate aging genes

\begin{tabular}{|c|c|c|c|c|c|}
\hline Index & Name & $P$-value & Adjusted $p$-value & Z-score & Combined score \\
\hline 1 & Pathways in cancer_Homo sapiens_hsa05200 & 4.07e-41 & $1.19 \mathrm{e}-38$ & -2.11 & 196.21 \\
\hline 2 & Proteoglycans in cancer_Homo sapiens_hsa05205 & $1.91 e-31$ & $2.78 \mathrm{e}-29$ & -1.99 & 140.58 \\
\hline 3 & Epstein-Barr virus infection_Homo sapiens_hsa05169 & $3.24 \mathrm{e}-30$ & $3.15 e-28$ & -1.9 & 128.92 \\
\hline 4 & Endocytosis_Homo sapiens_hsa04144 & $1.19 \mathrm{e}-28$ & $8.70 \mathrm{e}-27$ & -1.89 & 121.38 \\
\hline 5 & Regulation of actin cytoskeleton_Homo sapiens_hsa04810 & $4.30 \mathrm{e}-26$ & $2.51 e-24$ & -1.82 & 106.42 \\
\hline 6 & HTLV-I infection_Homo sapiens_hsa05166 & $1.01 e-25$ & $4.21 e-24$ & -1.79 & 103.2 \\
\hline 7 & Protein processing in endoplasmic reticulum_Homo sapiens_hsa04141 & $7.55 e-26$ & $3.68 \mathrm{e}-24$ & -1.69 & 98.04 \\
\hline 8 & Herpes simplex infection_Homo sapiens_hsa05168 & $1.24 \mathrm{e}-25$ & $4.54 \mathrm{e}-24$ & -1.61 & 92.36 \\
\hline 9 & PI3K-Akt signaling pathway_Homo sapiens_hsa04151 & $1.79 e-22$ & $4.96 \mathrm{e}-21$ & -1.83 & 91.82 \\
\hline 10 & Focal adhesion_Homo sapiens_hsa04510 & $1.12 \mathrm{e}-22$ & $3.63 e-21$ & -1.72 & 86.98 \\
\hline
\end{tabular}

In order to investigate the implication of the identified candidate genes in aging, we conducted a comprehensive analysis of 330 human pathways in the KEGG. Each of the pathways was examined in the seed and candidate genes, and direct association was detected in a number of instances. For example $I L 10$ activates STAT3 in the FOXO signaling pathway. In another example, $G A B 2$ has a regulatory role for PLCG2 in the osteoclast differentiation pathway, as well as an activating role in the chronic myeloid leukemia pathway. Likewise, FOS is an expression target for IL1O in the T cell receptor signaling pathway.

Enrichment analysis was performed using the Enrichr tool, based on the candidate genes and the negative genes [91] to examine whether the candidate and negative genes were correctly selected in respect with aging. The analysis of candidate genes was performed on 3531 genes from the rest of the test genes (i.e. excluding the positive seed and reliable negative genes). Most diseases that were associated with the candidate genes were diseases that occur with aging (e.g. colorectal cancer and diabetes) (Table 9).

Ontology analysis of the candidate genes was performed by FUNRICH [92] (Fig. 2), which revealed enrichment for the aging process and apoptosis. A list of all biological processes associated with the candidate aging gene is provided in Additional file 4 .

In the analysis of the enriched biological pathways, using Enrichr (Table 10), cancer pathways had the highest score. Interestingly, viral pathways (e.g. EBV and HSV) were enriched in the positive aging genes compartment, which is in line with the previously reported immunosenescence and activation of such viruses as a result of aging [93] .A list of all biological pathways of the candidate genes extracted by FUNRICH is provided in Additional file 5.

No specific age-related diseases were detected for the identified negative genes (Table 11), which supports the validity of the model training used. Ontology analysis of the reliable negative genes (Fig. 3), which was also performed by FUNRICH, revealed that most of the extracted processes had a general role in all cells and could not be related to specific aging processes. Analyzing the biologic pathways in the negative genes indicated pathways that were predominantly unrelated to the aging processes.

Based on the principle that similar disease genes are likely to have similar characteristics, some machine learning methods have been employed to predict new disease genes from known disease genes. Previous approaches developed a binary classification model that used known disease genes as a positive training set and unknown genes as a negative training set. However, the negative sets were often noisy because unknown genes could include healthy genes and positive collections. Therefore, the results presented by these methods may not be reliable. Using computational machine learning methods and similarity metrics, we identified reliable negative samples, and then tested the samples

Table 11 Indicative diseases associated with the reliable negative genes

\begin{tabular}{llllll}
\hline Index & Name & P-value & Adjusted $p$-value & Z-score & Combined score \\
\hline 1 & Cardiomyopathy,_dilated & 0.01658 & 0.2321 & -1.69 & 6.93 \\
2 & Cardiomyopathy & 0.03134 & 0.2416 & -1.61 & 5.57 \\
3 & Zellweger_syndrome & 0.01588 & 0.2321 & -1.06 & 4.41 \\
4 & Dystonia & 0.03451 & 0.2416 & -0.37 & 1.25 \\
\hline
\end{tabular}




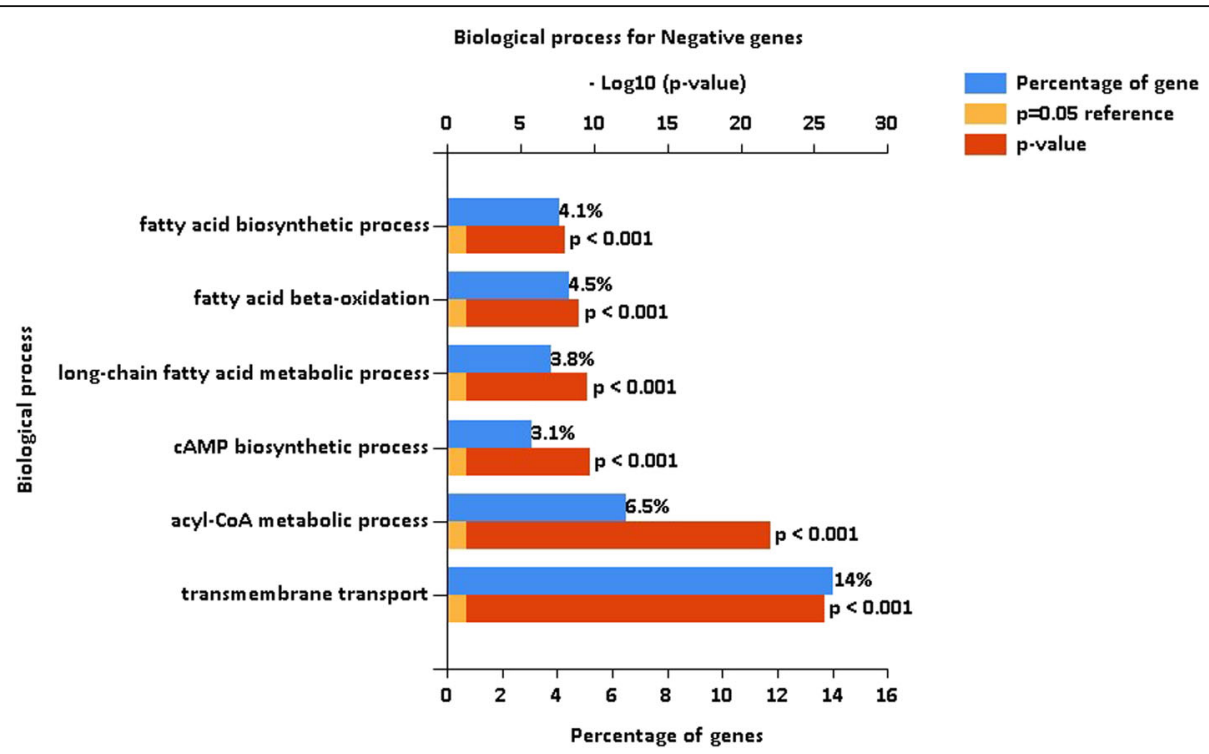

Fig. 3 Significant biological processes associated with the reliable negative genes

using a two-class classifier to identify novel positive aging genes in human.

\section{Conclusion}

We implemented 11 databases and several machine learning methods to rank the entire human genes, and predicted and prioritized over 3,000 novel candidate age-related genes based on significant ranking scores. These genes were supported by biological, ontology, and disease enrichment analyses. Future experimental research is warranted to verify the significance of the identified genes in human aging.

\section{Methods}

Algorithms

A classification method that is referred to as PUL is a similarity-based algorithm, in which reliable negative samples are extracted from unlabeled data. In addition, a binary classifier can be designed and used to identify the candidate genes (Fig. 4). Likewise, some methods identify reliable negative samples from unlabeled data, which are divided into three general categories: The first category has a two-stage strategy that runs a supervised algorithm on the data, by selecting reliable negative samples from within unlabeled instances [94]. The second category estimates

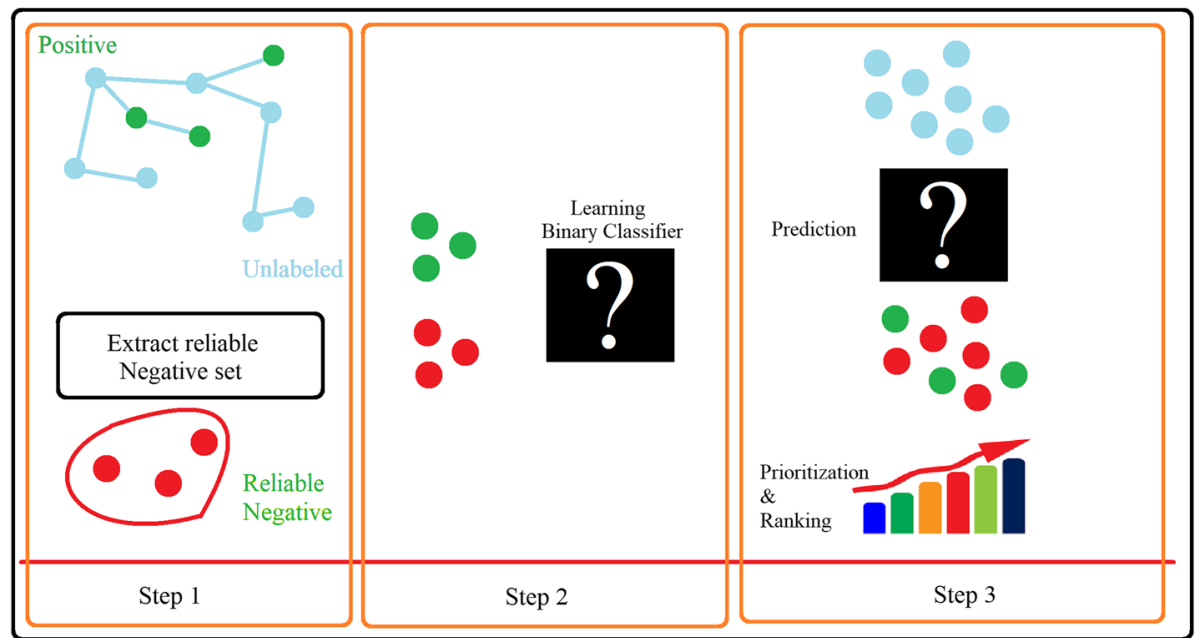

Fig. 4 The overall learning scheme based on positive and unlabeled samples, and extraction of reliable negative samples (step 1), construction of the binary Classifier (step 2), and prediction and prioritization of candidate genes (step 3) 
Table 12 Comparison of the evaluation metric across data sources

\begin{tabular}{|c|c|c|c|c|c|}
\hline Data source & Recall & Specificity & Precision & Accuracy & F_Measure \\
\hline Literature & 0.58098 & 0.61453 & 0.5888 & 0.5981 & 0.58478 \\
\hline Annotation & 0.77685 & 0.78668 & 0.76645 & 0.78165 & 0.77133 \\
\hline Pathways & 0.73268 & 0.74538 & 0.7204 & 0.73893 & 0.72605 \\
\hline Gene Ontology & 0.79303 & 0.78843 & 0.76315 & 0.78958 & 0.77703 \\
\hline Phenotype & 0.7946 & 0.81968 & 0.8158 & 0.80695 & 0.80488 \\
\hline Intrinsic properties & 0.67963 & 0.77035 & 0.78945 & 0.71835 & 0.72965 \\
\hline Sequence & 0.6901 & 0.72828 & 0.71713 & 0.70885 & 0.70305 \\
\hline Interaction & 0.7378 & 0.7724 & 0.76645 & 0.7543 & 0.75135 \\
\hline Gene expression & 0.75635 & 0.82148 & 0.82235 & 0.7864 & 0.78735 \\
\hline Regulatory & 0.77355 & 0.79203 & 0.77633 & 0.78163 & 0.77393 \\
\hline
\end{tabular}

the probability of positive samples by weighting positive and unlabeled data. The third category considers unlabeled data as negative samples with noise.

In this paper, a two-stage strategy was used to find a reliable negative sample and three different algorithms, Rocchio [95], NB [94], and Spy [96], were selected for implementation.

Bayesian classifiers that work explicitly on the possibilities of different assumptions, such as the NB classifier, which is one of the most efficient and most effective algorithms available for certain learning problems, have provided useful practical solutions [97].

The NB classifier can compete with other algorithms and in some cases, it works better than other algorithms [98]. A NB classifier can be considered as a simple Bayesian network, which is used for independence assumptions between features and classes. We chose NB based on the structure and nature of the data, the independent nature of each data source, and the high volume of the data and binary features.

Table 13 Data sources used in Naïve Bayes classifier for candidate aging genes

\begin{tabular}{|c|c|c|c|}
\hline $\begin{array}{l}\text { Data source } \\
\text { name }\end{array}$ & $\begin{array}{l}\text { Dataset } \\
\text { name }\end{array}$ & Features detail & Web address \\
\hline Literature & $\begin{array}{l}\text { OBO } \\
\text { AgeFactDB }\end{array}$ & $\begin{array}{l}\text { The ageing-related information included both by manual and automatic in- } \\
\text { formation extraction from the scientific literature. }\end{array}$ & $\begin{array}{l}\text { https://lov.linkeddata.es/dataset/lov/ } \\
\text { vocabs/obo } \\
\text { http://agefactdb.jenage.de/ }\end{array}$ \\
\hline $\begin{array}{l}\text { Functional } \\
\text { annotation }\end{array}$ & David & The list of all functional annotation. & https://david.ncifcrf.gov/ \\
\hline $\begin{array}{l}\text { Biological } \\
\text { pathways }\end{array}$ & $\begin{array}{l}\text { Reactome } \\
\text { Kegg }\end{array}$ & The list of biological pathway. & $\begin{array}{l}\text { https://reactome.org/ } \\
\text { https://www.genome.jp/kegg/ } \\
\text { pathway.html }\end{array}$ \\
\hline Gene Ontology & $\mathrm{GO}$ & $\begin{array}{l}\text { The Biological Process, Molecular Function, and Cellular Component } \\
\text { vocabularies. }\end{array}$ & http://www.geneontology.org/ \\
\hline Phenotype & $\begin{array}{l}\mathrm{HPO} \\
\mathrm{OMIM}\end{array}$ & The list of all ageing-related phenotype and associated gene. & $\begin{array}{l}\text { https://hpo.jax.org/ } \\
\text { https://www.omim.org/ }\end{array}$ \\
\hline $\begin{array}{l}\text { Intrinsic } \\
\text { properties }\end{array}$ & $\begin{array}{l}\text { Pfam } \\
\text { PDB }\end{array}$ & The chromosome number, location, gene segment, gene type, etc. & $\begin{array}{l}\text { https://pfam.xfam.org/ } \\
\text { https://www.rcsb.org/ }\end{array}$ \\
\hline Sequence & RefSeq & The list of all known active site, binding site, chain, etc. & https://www.ncbi.nlm.nih.gov/refseq/ \\
\hline $\begin{array}{l}\text { Protein-Protein } \\
\text { Interaction }\end{array}$ & $\begin{array}{l}\text { HPRD } \\
\text { String }\end{array}$ & $\begin{array}{l}\text { The list of each gene had a physical interaction with each of the positive } \\
\text { genes. }\end{array}$ & $\begin{array}{l}\text { http://www.hprd.org/ } \\
\text { https://string-db.org/ }\end{array}$ \\
\hline $\begin{array}{l}\text { Gene } \\
\text { expression }\end{array}$ & $\begin{array}{l}\text { GEO } \\
\text { HAGR }\end{array}$ & $\begin{array}{l}\text { The ageing-related expression included tissue type, overexpressed and under } \\
\text { expressed, etc. }\end{array}$ & $\begin{array}{l}\text { https://www.ncbi.nlm.nih.gov/geo/ } \\
\text { http://genomics.senescence.info/ } \\
\text { gene_expression/index.php }\end{array}$ \\
\hline Regulatory & RegNetwork & The list of all regulatory relationship, such as miRNA, Transcription factor, etc. & http://www.regnetworkweb.org/ \\
\hline Orthologues & $\begin{array}{l}\text { CDD } \\
\text { HomoloGene } \\
\text { OrthoDB }\end{array}$ & $\begin{array}{l}\text { The catalog of orthologous protein-coding genes across vertebrates and } \\
\text { known conserved domain. }\end{array}$ & $\begin{array}{l}\text { https://www.ncbi.nlm.nih.gov/ } \\
\text { Structure/cdd/cdd.shtml } \\
\text { https://www.ncbi.nlm.nih.gov/ } \\
\text { homologene } \\
\text { https://www.orthodb.org/ }\end{array}$ \\
\hline
\end{tabular}




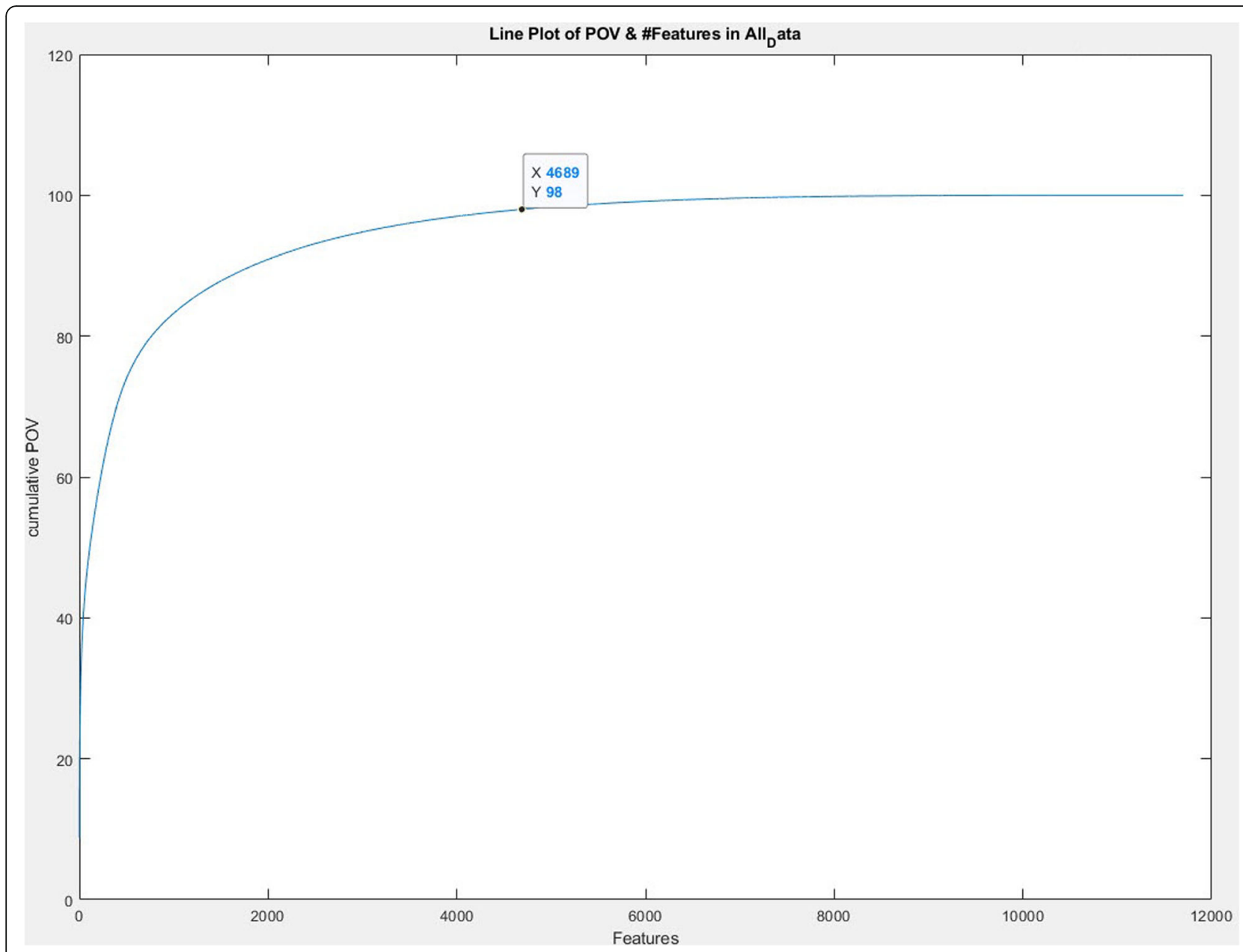

Fig. 5 The Percentage of Variance in Principal Component Analysis

An NB classifier with 4-fold cross validation was used to assess the diagnostic value of every data source. In this assessment, we identified how much of each data source alone was enough to identify the genes of aging (Table 12). The diagnostic value of all data sources was estimated at about 70\%, except the Literature. We used the data fusion method to get higher diagnostic value. Because of similar F Measure values, a fusion Kernel of equal weight was selected for each data source.

Since our main data did not contain any negative samples, training a model to identify and prioritize new positive genes was based on the three PUL algorithms. An NB classifier was designed following the extraction of a reliable negative sample and positive genes. Genes were assigned positive labels for the final ranking, using the weighting method according to the available data [7] .

The same weight was considered for ranking the candidate genes based on the selected sources. Similarities among the features were weighted in the seed genes and candidate genes, using the following formula, and then sorted based on their total weight:

$$
W(i)=\sum_{i=1}^{C} \sum_{j=1}^{F}\left(\text { Candidate }_{\text {Gene Feature }(i, j)} * \sum_{p=1}^{S} \operatorname{Seed}_{\operatorname{Genes}(p, j)}\right),
$$

where $(C)$ was the number of candidate genes $(n=$ $3531),(F)$ was the number of features $(n=11,698),(S)$ was the number of seed genes $(n=303)$ in the problem case, and $(W)$ was the weight of each candidate gene.

\section{Dataset}

Aggregate data from 11 human biology databases (Table 13), including 11,698 binary gene features, were collected for 19,462 genes, of which only 303 genes (seed genes) had positive labels for genes involved in aging, derived from the GeneAge database [99].

The vector of binary features consisted of 11 main parts, each part of which was equivalent to one of the data sources. The information for each data source was a boolean value, and if any gene contained this value, it scored 1, and otherwise, it scored 0 (Table 2). For example, a part of the biological pathway data contained 330 attributes, which were equivalent to a human 
pathway in KEGG. If the intended gene was located in this pathway, it scored 1, and otherwise, it scored 0. Also for interaction network data, if each gene had a physical interaction with each of the positive genes, it scored 1, and otherwise, 0 . These data were extracted from the String and HPRD databases.

Due to the large volume of features, we employed the PCA method to reduce the size of features. Following PCA implementation, our total data set was reduced to 4689 attributes, and the Percentage of Variance (POV) equaled 98\% (Fig. 5).

In addition, eight valid data sources from the UCI database (https://archive.ics.uci.edu/ml/index.php) were used to evaluate the efficiency of the algorithms. In each data set, one of the data classes with great sample frequency were unlabeled data. Using algorithms, we identified negative samples and compared them to the original data (Table 3 ).

\section{Supplementary information}

Supplementary information accompanies this paper at https://doi.org/10. 1186/s12864-019-6140-0.

Additional file 1: Comparison of evaluation metric of three algorithms in the UCl databases.

Additional file 2: Results of 10-fold cross-validation in the trained and test data.

Additional file 3: A list of all huma candidate positive aging genes.

Additional file 4: A list of all biological processes associated with the candidate aging genes.

Additional file 5: A list of all biological pathways of the candidate genes extracted by FUNRICH.

\section{Abbreviations}

GWAS: Genome-Wide Association Study; NB: Naïve Bayes; POV: Percentage of Variance; PPHAGE: Prediction and Prioritization of Human Aging Genes; PUL: Positive-unlabeled learning; ROC: Receiver Operating Characteristic

\section{Acknowledgements}

This research was jointly performed by the University of Social Welfare and Rehabilitation Sciences, Tehran, Iran, and University of Tehran, Iran.

\section{Authors' contributions}

MA designed the project, carried out the bioinformatics studies, and performed data analysis. MO contributed to supervision and data analysis, and wrote the manuscript. VRT participated in the statistical studies. AD helped in coordination. KK participated in designing the project and methodology, supervision and co-ordination. All authors read and approved the final manuscript.

\section{Funding}

Not applicable.

\section{Availability of data and materials}

Due to the large amount of data, please contact the authors for data requests.

\section{Ethics approval and consent to participate}

Not applicable.

\section{Consent for publication}

Not applicable.

\section{Competing interests}

The authors declare that they have no competing interests.

\section{Author details}

${ }^{1}$ Department of Bioinformatics, Kish International Campus University of Tehran, Kish, Iran. 'Laboratory of Complex Biological Systems and Bioinformatics (CBB), Department of Bioinformatics, Institute of Biochemistry and Biophysics (IBB), University of Tehran, Tehran, Iran. ${ }^{3}$ Iranian Research Center on Aging, University of Social Welfare and Rehabilitation Sciences, Tehran, Iran. ${ }^{4}$ Department of Statistics, Faculty of Mathematical Sciences and Computer, Allameh Tabataba'i University, Tehran, Iran.

Received: 22 March 2019 Accepted: 25 September 2019

Published online: 09 November 2019

References

1. Korf B, Rimoin D, O'Connor J, Pyeritz R. Nature and frequency of genetic disease. In: Rimoin D, O'Connor J, Pyeritz R, Korf B, editors. Principles and Practice of Medical Genetics. Amsterdam: Elsevier; 2008. pp. 49-51.

2. Yang $P$, et al. Positive-unlabeled learning for disease gene identification. Bioinformatics. 2012;28(20):2640-7.

3. Al-Turaiki IM, et al. Computational approaches for gene prediction: a comparative survey. Berlin: Springer; 2011.

4. Barabási A-L, Gulbahce N, Loscalzo J. Network medicine: a network-based approach to human disease. Nat Rev Genet. 2011;12(1):56.

5. Piro RM, Di Cunto F. Computational approaches to disease-gene prediction: rationale, classification and successes. FEBS J. 2012;279(5):678-96.

6. Sakai T, Niu G, Sugiyama M. Correction to: semi-supervised AUC optimization based on positive-unlabeled learning. Mach Learn. 2018; 107(4):795.

7. Chen $Y$, et al. In silico gene prioritization by integrating multiple data sources. PLoS One. 2011;6(6):e21137.

8. Lachmann R, Schulze S, Nieke M, Seidl C, \& Schaefer I. System-level test case prioritization using machine learning. In 2016 15th IEEE International Conference on Machine Learning and Applications (ICMLA). IEEE; 2016. pp. 361-368.

9. Chen X, Yan GY. Semi-supervised learning for potential human microRNAdisease associations inference. Sci Rep. 2014;4:5501.

10. Nguyen T-P, Ho TB. Detecting disease genes based on semi-supervised learning and protein-protein interaction networks. Artif Intell Med. 2012; 54(1):63-71.

11. Zitnik $M$, et al. Machine learning for integrating data in biology and medicine: principles, practice, and opportunities. Inf Fusion. 2019;50:71-91.

12. Oneto L, Bunte $\mathrm{K}$, Schleif FM. Advances in artificial neural networks, machine learning and computational intelligence: Selected papers from the 26th European Symposium on Artificial Neural Networks, Computational Intelligence and Machine Learning (ESANN 2018). Neurocomputing. 2019; 342:1-5.

13. Bromberg Y. Chapter 15: disease gene prioritization. PLoS Comput Biol. 2013;9(4):e1002902.

14. Hutz JE, et al. CANDID: a flexible method for prioritizing candidate genes for complex human traits. Genet Epidemiol. 2008;32(8):779-90.

15. Doncheva NT, et al. Recent approaches to the prioritization of candidate disease genes. Wiley Interdiscip Rev Syst Biol Med. 2012;4(5):429-42.

16. Karczewski K, Snyder MP. Integrative omics for health and disease. Nat Rev Genet. 2018;19(5):299.

17. Tranchevent $L-C$, et al. Candidate gene prioritization with Endeavour. Nucleic Acids Res. 2016;44(W1):W117-21.

18. Zakeri $P$, et al. Gene prioritization using Bayesian matrix factorization with genomic and phenotypic side information. Bioinformatics. 2018; 34(13):i447-56.

19. Sakar CO, et al. A comparative analysis of speech signal processing algorithms for Parkinson's disease classification and the use of the tunable Q-factor wavelet transform. Appl Soft Comput. 2019;74:255-63.

20. McDermott J, Forsyth RS. Diagnosing a disorder in a classification benchmark. Pattern Recognit Lett. 2016;73:41-3.

21. Pelckmans $K$, et al. The differogram: non-parametric noise variance estimation and its use for model selection. Neurocomputing. 2005;69(1-3): 100-22.

22. Sigillito VG, et al. Classification of radar returns from the ionosphere using neural networks. Johns Hopkins APL Tech Dig. 1989;10(3):262-6. 
23. Bock RK, et al. Methods for multidimensional event classification: a case study using images from a Cherenkov gamma-ray telescope. Nucl Instrum Methods Phys Res Sect A: Accelerators, Spectrometers, Detectors and Associated Equipment. 2004;516(2):511-28.

24. Elter M, Schulz-Wendtland R, Wittenberg T. The prediction of breast cance biopsy outcomes using two CAD approaches that both emphasize an intelligible decision process. Med Phys. 2007;34(11):4164-72.

25. Street WN, Wolberg WH, Mangasarian OL. Nuclear feature extraction for breast tumor diagnosis. In Biomedical image processing and biomedical visualization (Vol. 1905, pp. 861-870). Int Soc Optics and Photonics. 1993; 1905:861-870

26. Gorman RP, Sejnowski TJ. Analysis of hidden units in a layered network trained to classify sonar targets. Neural Netw. 1988;1(1):75-89.

27. Chang CC, Lin CJ. LIBSVM: a library for support vector machines. ACM Trans Intell Syst Technol. 2011;2(3):27.

28. Lin C, et al. LibD3C: ensemble classifiers with a clustering and dynamic selection strategy. Neurocomputing. 2014;123:424-35.

29. Hall M, et al. The WEKA data mining software: an update. ACM SIGKDD Explorations News. 2009:11(1):10-8.

30. Peng $\mathrm{H}$, et al. Feature selection based on mutual information: criteria of max-dependency, max-relevance, and min-redundancy. IEEE Trans Pattern Anal Mach Intell. 2005;27(8):1226-38.

31. Chen J, et al. ToppGene Suite for gene list enrichment analysis and candidate gene prioritization. Nucleic Acids Res. 2009;37(Web Server issue):W305-11.

32. Feser J, Tyler J. Chromatin structure as a mediator of aging. FEBS Lett. 2011; 585(13):2041-8.

33. Glass D, et al. Gene expression changes with age in skin, adipose tissue, blood and brain. Genome Biol. 2013;14(7):R75

34. Loesch DZ, et al. Evidence for the toxicity of bidirectional transcripts and mitochondrial dysfunction in blood associated with small CGG expansions in the FMR1 gene in patients with parkinsonism. Genet Med. 2011;13(5): 392-9.

35. Russo A, et al. Regulatory role of rpL3 in cell response to nucleolar stress induced by Act D in tumor cells lacking functional p53. Cell Cycle. 2016; 15(1):41-51

36. Li B, et al. WNT5A signaling contributes to Abeta-induced neuroinflammation and neurotoxicity. PLoS One. 2011;6(8):e22920.

37. Belkina AC, Denis GV. Obesity genes and insulin resistance. Curr Opin Endocrinol Diabetes Obes. 2010;17(5):472-7.

38. Wang F, et al. Brd2 disruption in mice causes severe obesity without type 2 diabetes. Biochem J. 2009;425(1):71-83.

39. Rendina D, et al. FSHR gene polymorphisms influence bone mineral density and bone turnover in postmenopausal women. Eur J Endocrinol. 2010; 163(1):165-72

40. Chen J, et al. A prospective study of N-acetyltransferase genotype, red meat intake, and risk of colorectal cancer. Cancer Res. 1998;58(15):3307-11.

41. Torabi Moghadam B, et al. Combinatorial identification of DNA methylation patterns over age in the human brain. BMC Bioinformatics. 2016;17(1):393.

42. Deschênes $M$, Chabot $B$. The emerging role of alternative splicing in senescence and aging. Aging Cell. 2017;16(5):918-33.

43. Tabrez S, et al. A putative association of interleukin-10 promoter polymorphisms with cardiovascular disease. IUBMB Life. 2017:69(7):522-7.

44. La Manna G, et al. Cardiovascular disease in kidney transplant recipients: the prognostic value of inflammatory cytokine genotypes. Transplantation. 2010; 89(8):1001-8.

45. da Silva Pereira BL, et al. Interleukin-10 -1082A>G (rs1800896) polymorphism is associated with diabetic retinopathy in type 2 diabetes. Diabetes Res Clin Pract. 2018;138:187-92.

46. Meenakshi $P$, et al. Effect of IFN-gamma, IL-12 and IL-10 cytokine production and mRNA expression in tuberculosis patients with diabetes mellitus and their household contacts. Cytokine. 2016;81:127-36.

47. Yin YW, et al. Association between interleukin 10 gene -1082 A/G polymorphism and the risk of type 2 diabetes mellitus: a meta-analysis of 4250 subjects. Cytokine. 2013;62(2):226-31

48. Banday $M Z$, et al. Interleukin-10 -592C/A, but not-1082A/G promoter single nucleotide polymorphism, is associated with a decreased risk of colorectal cancer in an ethnic Kashmiri population: a case-control study. Eur J Cancer Prev. 2017;26(6):476-90.

49. Nosho $\mathrm{K}$, et al. Association of Fusobacterium nucleatum with immunity and molecular alterations in colorectal cancer. World J Gastroenterol. 2016;22(2):557-66.
50. Huo Y, et al. Cortisol is associated with low frequency of interleukin 10producing B cells in patients with atherosclerosis. Cell Biochem Funct. 2017; 35(3):178-83.

51. Kang JG, et al. Low ambient oxygen prevents atherosclerosis. J Mol Med (Berl). 2016;94(3):277-86.

52. Liu Z, et al. Lack of association between IL-10 and IL-18 gene promoter polymorphisms and Parkinson's disease with cognitive impairment in a Chinese population. Sci Rep. 2016;6:19021.

53. Pascale $E$, et al. Lack of association between IL-1 beta, TNF-alpha, and IL-10 gene polymorphisms and sporadic Parkinson's disease in an Italian cohort. Acta Neurol Scand. 2011;124(3):176-81.

54. Bialecka M, et al. Interleukin-10 (IL10) and tumor necrosis factor alpha (TNF) gene polymorphisms in Parkinson's disease patients. Parkinsonism Relat Disord. 2008;14(8):636-40.

55. Tedone $\mathrm{E}$, et al. Leukocyte telomere length in Alzheimer's disease patients with a different rate of progression. J Alzheimers Dis. 2015;46(3):761-9.

56. Asselineau $D$, et al. Interleukin-10 production in response to amyloid-beta differs between slow and fast decliners in patients with Alzheimer's disease. J Alzheimers Dis. 2015:46(4):837-42.

57. Medway C, et al. The sex-specific associations of the aromatase gene with Alzheimer's disease and its interaction with IL10 in the Epistasis Project. Eur J Hum Genet. 2014;22(2):216-20.

58. Lorenzo N, et al. APL-2, an altered peptide ligand derived from heat-shock protein 60 , induces interleukin-10 in peripheral blood mononuclear cell derived from juvenile idiopathic arthritis patients and downregulates the inflammatory response in collagen-induced arthritis model. Clin Exp Med. 2015;15(1):31-9.

59. Falcon $\mathrm{CR}$, et al. In vivo expression of recombinant pregnancy-specific glycoprotein 1a inhibits the symptoms of collagen-induced arthritis. Am J Reprod Immunol. 2014;72(6):527-33.

60. Chung S, et al. Distinct role of FoxO1 in M-CSF- and GM-CSF-differentiated macrophages contributes LPS-mediated IL-10: implication in hyperglycemia. J Leukoc Biol. 2015;97(2):327-39.

61. Nunes RB, et al. Aerobic exercise improves the inflammatory profile correlated with cardiac remodeling and function in chronic heart failure rats. Clinics (Sao Paulo). 2013:68(6):876-82.

62. Tekin A, et al. Short-term effects of fluvastatin therapy on plasma interleukin-10 levels in patients with chronic heart failure. Coron Artery Dis. 2008;19(7):513-9.

63. Kaur K, Sharma AK, Singal PK. Significance of changes in TNF-alpha and IL10 levels in the progression of heart failure subsequent to myocardial infarction. Am J Physiol Heart Circ Physiol. 2006;291(1):H106-13.

64. Chen J, et al. Mutations in FYCO1 cause autosomal-recessive congenital cataracts. Am J Hum Genet. 2011;88(6):827-38.

65. Pras $\mathrm{E}$, et al. A gene causing autosomal recessive cataract maps to the short arm of chromosome 3. Isr Med Assoc J. 2001;3(8):559-62.

66. Lill CM, et al. Comprehensive research synopsis and systematic metaanalyses in Parkinson's disease genetics: the PDGene database. PLoS Genet. 2012;8(3):e1002548.

67. Liu X, et al. Genome-wide association study identifies candidate genes for Parkinson's disease in an Ashkenazi Jewish population. BMC Med Genet. 2011;12:104.

68. Do CB, et al. Web-based genome-wide association study identifies two novel loci and a substantial genetic component for Parkinson's disease. PLoS Genet. 2011;7(6):e1002141.

69. Karic A, et al. Identifying candidate genes for Parkinson's disease by integrative genomics method. Biochem Med (Zagreb). 2011;21(2):174-81.

70. Simon-Sanchez J, et al. Genome-wide association study reveals genetic risk underlying Parkinson's disease. Nat Genet. 2009;41(12):1308-12.

71. $\mathrm{Ma} \mathrm{L}$, et al. PCLO variants are nominally associated with early-onset type 2 diabetes and insulin resistance in Pima Indians. Diabetes. 2008; 57(11):3156-60.

72. Zheng JY, et al. Associations of rs3740677 within GAB2 gene with LOAD in Chinese Han population. Mol Neurobiol. 2017;54(6):4015-20.

73. Hu Y, et al. GAB2 rs2373115 variant contributes to Alzheimer's disease risk specifically in European population. J Neurol Sci. 2017;375:18-22.

74. Zou F, et al. Linking protective GAB2 variants, increased cortical GAB2 expression and decreased Alzheimer's disease pathology. PLoS One. 2013; 8(5):e64802.

75. Wang $\mathrm{G}$, et al. Association study of the GAB2 gene with the risk of Alzheimer disease in the chinese population. Alzheimer Dis Assoc Disord. 2011;25(3):283-5. 
76. Ding $C$, et al. Elevated Gab2 induces tumor growth and angiogenesis in colorectal cancer through upregulating VEGF levels. J Exp Clin Cancer Res. 2017;36(1):56.

77. Matsumura T, et al. Clinical significance of GAB2, a scaffolding/docking protein acting downstream of EGFR in human colorectal cancer. Ann Surg Oncol. 2014;21(Suppl 4):S743-9.

78. Wada T, et al. The molecular scaffold Gab2 is a crucial component of RANK signaling and osteoclastogenesis. Nat Med. 2005;11(4):394-9.

79. Dehghan A, et al. Genome-wide association study for incident myocardial infarction and coronary heart disease in prospective cohort studies: the CHARGE consortium. PLoS One. 2016;11(3):e0144997.

80. Aziz MA, et al. Integrated exon level expression analysis of driver genes explain their role in colorectal cancer. PLoS One. 2014;9(10):e110134.

81. Gao C, et al. RBFox1-mediated RNA splicing regulates cardiac hypertrophy and heart failure. J Clin Invest. 2016;126(1):195-206.

82. Sengupta N, et al. Analysis of colorectal cancers in British Bangladeshi identifies early onset, frequent mucinous histotype and a high prevalence of RBFOX1 deletion. Mol Cancer. 2013;12:1.

83. Zhang GJ, et al. MicroRNA-106b promotes colorectal cancer cell migration and invasion by directly targeting DLC1. J Exp Clin Cancer Res. 2015;34:73.

84. Park H, et al. Genomic alterations in BCL2L1 and DLC1 contribute to drug sensitivity in gastric cancer. Proc Natl Acad Sci U S A. 2015;112(40):12492-7.

85. Lin $B$, et al. Uncovering the rare variants of DLC1 isoform 1 and their functional effects in a Chinese sporadic congenital heart disease cohort. PLoS One. 2014;9(2):e90215.

86. Schjeide BM, et al. GAB2 as an Alzheimer disease susceptibility gene: followup of genomewide association results. Arch Neurol. 2009;66(2):250-4.

87. Edwards DRV, et al. Linkage and association of successful aging to the $6 \mathrm{q} 25$ region in large Amish kindreds. Age (Dordr). 2013;35(4):1467-77.

88. Welle $\mathrm{S}$, et al. Gene expression profile of aging in human muscle. Physiol Genomics. 2003;14(2):149-59.

89. McClay $\mathrm{JL}$, et al. A methylome-wide study of aging using massively parallel sequencing of the methyl-CpG-enriched genomic fraction from blood in over 700 subjects. Hum Mol Genet. 2014;23(5):1175-85.

90. Cribbs DH, et al. Extensive innate immune gene activation accompanies brain aging, increasing vulnerability to cognitive decline and neurodegeneration: a microarray study. J Neuroinflammation. 2012;9:179.

91. Kuleshov MV, et al. Enrichr: a comprehensive gene set enrichment analysis web server 2016 update. Nucleic Acids Res. 2016:44(W1):W90-7.

92. Pathan $\mathrm{M}$, et al. FunRich: an open access standalone functional enrichment and interaction network analysis tool. Proteomics. 2015;15(15):2597-601.

93. Mancuso $\mathrm{S}$, et al. Immunosenescence and lymphomagenesis. Immun Ageing. 2018;15:22.

94. Zhang B, Zuo W. Learning from positive and unlabeled examples: a survey in 2008 International Symposiums on Information Processing; 2008.

95. Li X, Liu B. Learning to classify texts using positive and unlabeled data. In: Proceedings of the 18th international joint conference on Artificial intelligence. Acapulco: Morgan Kaufmann Publishers Inc.; 2003. p. 587-92.

96. Liu B, et al. Partially supervised classification of text documents. In: Proceedings of the Nineteenth International Conference on Machine Learning. Morgan: Kaufmann Publishers Inc.; 2002. p. 387-94.

97. Al-Aidaroos K, Bakar A, Othman Z. Medical data classification with Naive Bayes approach. Inf Technol J. 2012;11(9):1166-74.

98. Tanwani AK, et al. Guidelines to select machine learning scheme for classification of biomedical datasets. In: European Conference on Evolutionary Computation, Machine Learning and Data Mining in Bioinformatics. Berlin, Heidelberg: Springer; 2009.

99. Tacutu R, et al. Human ageing genomic resources: new and updated databases. Nucleic Acids Res. 2018;46(D1):D1083-d1090.

\section{Publisher's Note}

Springer Nature remains neutral with regard to jurisdictional claims in published maps and institutional affiliations.

Ready to submit your research? Choose BMC and benefit from:

- fast, convenient online submission

- thorough peer review by experienced researchers in your field

- rapid publication on acceptance

- support for research data, including large and complex data types

- gold Open Access which fosters wider collaboration and increased citations

- maximum visibility for your research: over $100 \mathrm{M}$ website views per year

At BMC, research is always in progress.

Learn more biomedcentral.com/submissions 